\title{
The Five Cs of Digital Curation: Supporting Twenty-First- Century Teaching and Learning
}

\author{
Mark E. Deschaine, PhD \\ Assistant Professor, Department of Educational Leadership \\ Central Michigan University \\ Sue Ann Sharma, PhD \\ Visiting Assistant Professor, Department of Reading and Language Art \\ Oakland University
}

Digital curation is a process that allows university professors to adapt and adopt resources from multidisciplinary fields to meet the educational needs of twenty-firstcentury learners. Looking through the lens of new media literacy studies (Vasquez,

Harste, \& Albers, 2010) and new literacies studies (Gee, 2010), we propose that university professors be savvy consumers of multimedia through purposeful content curation. In this paper, we will discuss practices that university professors may use

to transform teaching and learning through effective collection, categorization,

critiquing, conceptualization, and circulation of resources deemed to have curricular and content standards value.

University professors spend a considerable amount of time identifying, locating, downloading, categorizing, manipulating, presenting, and assessing academic materials to collect and use with their students. This process is not new. Although these types of activities have occurred for years, technological advances have dramatically increased the ability of university professors to do all of these things in a much more efficient and effective manner. Although the level of efficiency has increased, so too has the range of digital materials available and the amount of information that needs to be considered. These new instructional assets are a result of evolving new technologies. To better maximize the potential of these digital materials, assets must be organized well. This creates a need for university professors, as Scime (2015) suggests, to "collect, preserve, attend to, and create themed content packages that together, offer a unique perspective" (Introduction section, para. 3).

This paper proposes that university professors have the opportunity to become, of necessity, savvy consumers of digital material and resources through purposeful content curation processes. Through the progression of effective collection, categorization, critiquing, conceptualization, and circulation of resources, university professors will be able to more effectively integrate the plethora of potential resources they encounter in today's ever changing digital landscape. As educators responsible for imparting twenty-first-century skills, we argue that it is essential for teacher educators to become digital curators by identifying and utilizing resources that are reflective, relevant, and representative of the goals and objectives contained within the curriculum.

\section{What is Digital Curation?}

Our contention is that university professors are confronted with an onslaught of digital materials and resources that have the potential to dramatically enhance teaching and learning practices if intentionally curated. To do this, digital materials need to be mindfully mined, organized, and archived appropriately. We refer to this process as digital curation.

For some, digital curation is a new idea, but in reality educators have long been curators. For example, archeologists have served in dual roles both as "scientists and cultural resource managers" (Christenson, 1979, p. 161). In the same way, university professors perform dual roles as content collectors of their discipline and transmitters of scholarly work to current and future generations. It is 
important to recognize that "there have been people doing different aspects of data curation and digital preservation for decades" (Yakel, 2007, p. 335) and that the term digital curation "can be perceived differently by different individuals and disciplines" (Beagrie, 2008, p. 4). Therefore, we define digital curation as

the creation, management, and use of digital materials...for a wide range of activities.... The term digital curation is increasingly being used for the actions needed to add value to and maintain these digital assets over time for current and future generations of users. (Beagrie, 2008, p. 3)

The collection and assembling of instructional materials is not enough; a value judgment needs to be made as to the appropriateness of the material for the content being taught. Collections transform into curations once a value judgment about the appropriateness of the material being considered is made. Consideration needs to be given to the relevancy, accuracy, authenticity, and appropriateness of the materials in question.

A collection can be transformed into an appropriate instructional source through an intentional process that forms the basis of curation. The process of digital curation provides a means to support teaching through the careful management and assembly of digital resources; it is a way of collecting and creating a retrospective of what you are trying to attend to during the instructional process.

\section{Why is Digital Curation Relevant Today?}

There is an increased need for faculty to realize the impact that digital curation has on their content due to the speed at which data and information are being developed, acquired, and utilized. Traditionally, research and teaching agendas were curated primarily through the use of journals and presentations; however, with the advances in technology, enhanced tools allow researchers to preserve their work in new venues and formats to reach new audiences. These evolving capabilities afford increasingly sophisticated opportunities for interactive multidisciplinary scholarship that enrich educational practices. Yakel, Conway, Hedstrom, and Wallace (2011) argue that

Digital information is all around us. More and more information is either born digital or digitally reformatted. A new generation of professionals is needed who are comfortable working in hybrid (digital and analog) environments and capable of managing media-neutral information throughout its life cycle. (p. 23)

Reform efforts in education have taken hold, and there exists a need for structures to be developed to document program effectiveness. Twenty-firstcentury educators must ensure that the content and sources they are using align with the expectations of their credentialing organization. Additionally, and most importantly, these resources have to be relevant to meet their students' needs. These efforts become

Curating digital resources allows university professors to connect and transcend academic content areas to broader issues...

supportive of not only the needs of student constituency, but also of their larger content field of study. They also are designed to meet the needs of the organizations responsible for program assessment and evaluation. Digital curation is a process that can provide such documentation.

Digital curation allows faculty members to enhance their work through the utilization of cross-disciplinary forays and create broader understandings of concepts and topics in ways seldom available in the past. Curating digital resources allows university professors to connect and transcend academic content areas to broader issues such as race, ethnicity, socioeconomic status, gender, disability 
status, sexual orientation, religious affiliation, or nationality by bringing resources that are reflective of different perspectives and orientations. Effective curation can be utilized as a vehicle for what Wals (2007) describes as social justice: its perspectives, challenges, and praxis.

The units of information, as well as the materials that we utilize today, may be out of date tomorrow. Curation allows faculty members to capitalize upon the need to preserve for posterity the work that occurs during their tenure. The hyperlinked structure of today's web, with the ability to record and digitally preserve content, allows faculty to articulate, amalgamate, and amplify their voice.

\section{Theoretical Framework for Digital Curation}

In an age of easy access and production of media through a variety of technologies, we draw upon the fields of new media literacy studies (Vasquez, Harste, \& Albers, 2010) and new literacies studies (Gee, 2010) for developing a framework to better understand how digital curation can facilitate new ways of

This process requires the university pooling skills and distilling professor to become critically conscious about his or her own beliefs, to be aware of the larger community voices in their selection for curated materials, and to become an agent for community action in their selections for curation.

knowledge to transform teaching and learning. Looking through the lens of new media literacy studies (Vasquez et al., 2010), we propose it essential for university professors to engage in reflective and critical investigations of the materials being considered for curation. Developing multimedia resources through digital curation reflects the orientation, advocacy, and perspectives of not only the creator's local sphere of influence but also that of their larger scholarly community. The efforts of faculty are energized and magnified through Internet access and the availability across all communities of learners, practitioners, teachers, researchers, and citizens.

In using the lens of new literacies studies (Gee, 2010), we view the process of digital curation as the utilization of different technologies to give and acquire meaning. Technologies provide opportunity for new meanings and conceptualizations of information through which the faculty members amalgamate, re-conceptualize, and repackage content. These technologies also allow for the potential of co-constructed and reconstructed insights and are reflected in the development of the curated instructional materials.

\section{The Five Cs of Digital Curation}

We propose that digital curation is a process of five Cs: collect, categorize critique, conceptualize, and circulate based on the framework of new media literacy studies (Vasquez et al., 2010) and new literacies studies (Gee, 2010). This process requires the university professor to become critically conscious about his

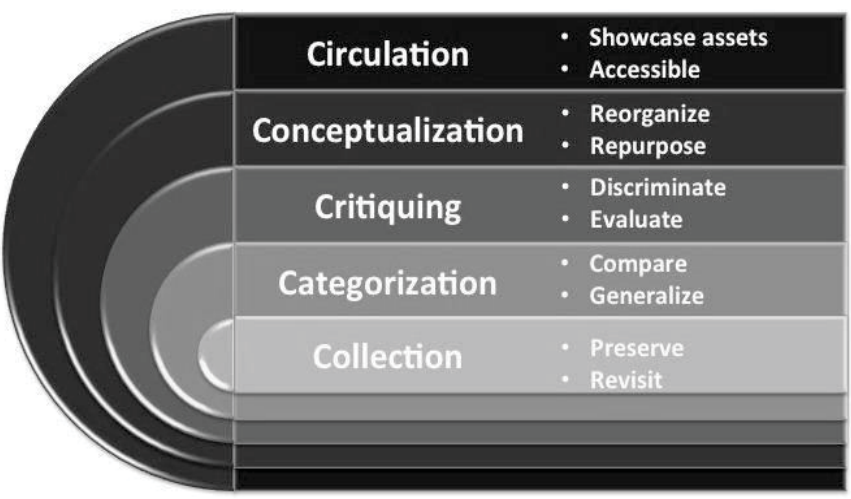

Figure 1. A Digital Curation Framework 
or her own beliefs, to be aware of the larger community voices in their selection for curated materials, and to become an agent for community action in their selections for curation. This is reflected in the amalgamation, reconceptualization, and repackaging of items during the digital curation process.

It is essential for faculty members who engage in the process of digital content curation to be aware of and become actively engaged in critical readings in their field of study and of the world. Effective curation is a multistep, developmentally sequenced endeavor; each step leads to the next, with greater and greater refinement of content resulting from the reflective and recurrent process. The five Cs or phases of digital curation are as follows: collection, categorization, critiquing, conceptualization, and circulation.

\section{Collection}

Typically, in the collection phase, university faculty engage in amassing items in an effort to preserve them for further study. At this stage, any rational representation of the broad academic topic is considered for digital collection. The collecting of appropriate artifacts for educational purposes has been done for years in specialized fields of study such as museum science, archaeology, and library science. We contend that transformative technologies and access to the Internet have expanded the capabilities of faculty who, in other fields of study, are interested in preserving their work for posterity. This expansion allows them to focus on collecting resources that are broadly similar to their scholarship and academic responsibility as well as their broader field of study.

Comparison and cataloging are two key activities of the collection stage. It is prudent for university faculty to revisit their conceptualization of the items they are collecting. One structure for this is to compare new items collected with existing exemplars. As faculty members engage in a revisiting of the broader theme, they also ensure that current and future collections meet the broad category for inclusion. During the collection phase, it is necessary and appropriate for faculty to document and catalog where their items were acquired from, so that items from future forays can be more easily amassed. Cataloging the collection is an important activity to ensure the integrity of the content, maintain the ethics of the field, and preserve the historical perspective.

\section{Categorization}

When a faculty member begins the categorization phase, he or she is primarily concerned with a comparison of the items collected to refine their conceptualization of what the exemplar is to look like. Generalizations are made about broad attributes, and it is incumbent upon the faculty member to identify the aspects of the collection that make these items mutually important and cohesive. It is during this phase that the faculty member critically reflects upon why certain items need to be included and, conversely, why certain items need to be excluded from the conceptualization.

\section{Critiquing}

In the critique stage, faculty members perform a more refined exploration of the items they have assembled. They start discriminating, evaluating, and judging the merits of each item in the categorized collection. It is during this stage that university faculty members start aggregating only the most salient exemplars of the topic they are studying. The quality and integrity of the curated material relies heavily upon a critical eye, professional judgment, sound reasoning, and justification for either inclusion or exclusion of items. This process is essential to the growth and development of the academic field. University professionals must take care during this stage to ensure that their work is thorough, objective, data 
driven, and research- grounded, so that only the most appropriate items are selected for further inclusion in the curation process.

\section{Conceptualization}

The conceptualization of content requires the professor to reorganize the items and materials they are using in such a way that linkages are made between disparate artifacts. It is during this stage that the university faculty also might

It provides the faculty member with an avenue to demonstrate value-added perspectives by making collections available for future academics.

repurpose items selected, so that new truths can be not only identified but also exemplified. During the conceptualization phase, documentation and demonstration of theory take place. It is an opportunity for the faculty member to provide working examples of their theoretical and conceptual frameworks.

\section{Circulation}

The last stage of the curation process allows faculty members to circulate their ever-evolving collections. It provides them with an opportunity to showcase assets through the utilization of multimedia, and multidisciplinary and multitheoretical avenues. There are many free content curation tools available on the Internet; selection of these tools is a matter of personal preference.

The circulation of developed and curated items allows the university personnel to have their work shared and saved for posterity. It provides the faculty member with an avenue to demonstrate value-added perspectives by making collections available for future academics.

As the process of digital curation increases in higher education, it is anticipated that multidisciplinary learning communities will become much more interactive. The movement towards open-sourced and open access learning materials will increase the likelihood that curated materials will allow future students and academics to be not just consumers of the curated product but also contributors to future insights and breakthroughs.

\section{Summary}

We conclude that digital curation affords university professors a unique opportunity to develop effective teacher education and professional development materials. The five Cs of digital curation is a process that allows university professors to adapt and adopt resources from multidisciplinary fields to meet the educational needs of twenty-first-century learners.

\section{References}

Beagrie, N. (2008). Digital curation for science, digital libraries, and individuals. International Journal of Digital Curation, 1(1), 3-16.

Christenson, A. L. (1979). The role of museums in cultural resource management. American Antiquity, 44(1), 161-163.
Gee, J. P. (2010). A situatedsociocultural approach to literacy and technology. In A. E. Baker (Ed.), The new literacies: Multiple perspectives on research and practice (pp. 165-193). New York, NY: The Guilford Press.

Scime, E. (2015). The content strategist as digital curator. Retrieved from http://alistapart.com/article/contentstrategist-as-digital-curator 
Vasquez, V., Harste, J. C., \& Albers, P. (2010). From the personal to the worldwide web: Moving teachers into positions of critical interrogation. In A. E. Baker (Ed.), The New Literacies: Multiple Perspectives on Research and Practice (pp. 265-284). New York, NY: The Guilford Press.

Wals, A. E. J. (Ed.). (2007). Social

learning towards a sustainable world:

Principles, practice, and praxis.

Retrieved from

http://www.wageningenacademic.com/ clientFiles/download/sociallearning-e.pdf
Yakel, E. (2007). Digital curation. OCLC Systems \& Services, 23(4), 335-340.

Yakel, E., Conway, P., Hedstrom, M., \& Wallace, D. (2011). Digital curation for digital natives. Journal of Education for Library and Information Science, 23-31.

Mark E. Deschaine is an Assistant Professor in the Department of Educational Leadership in the College of Education and Human Services at Central Michigan University. He has extensive local, state, and national experience in training and development of faculty in the integration of technology into their curriculum, special education issues, and effective instructional practices. He holds Michigan certification and endorsements as a teacher, a special educator, and building as well as central office administrator. Deschaine's research agenda focuses on leadership issues, effective education, administration of special education, educational technology, professional development, and special needs transportation.

Sue Ann Sharma is a Visiting Assistant Professor of Reading and Language Arts in the School of Education at Oakland University. She holds appointments on the International Reading Association's Literacy Reform Task Force, Michigan Reading Association's Board of Directors and Michigan Reading Journal Review Board. Sharma's expertise, research agenda, and passion lie in the areas of diversity related to culturally responsive teaching; the possibilities and challenges for teaching reading, writing, and language with new media; and online learning as it relates to the development of learning communities, and coaching. She has authored articles and presented internationally on these topics. 